Supporting Information for

\title{
Diastereospecific Photocyclization of Isopropylbenzophenone Derivatives in Crystals and the Morphology Changes
}

Hideko Koshima, ${ }^{*}$ Michitaro Fukano and Hidehiro Uekusa

\section{Table of contents}

1. General experimental methods

p. S1

2. ${ }^{1} \mathrm{H}$ NMR spectral data of $(S)-\mathbf{1},(R, S)-\mathbf{2}$ and $(S, S)-\mathbf{2}$

p. $S 2-S 4$ 


\section{General experimental methods}

${ }^{1} \mathrm{H}-\mathrm{NMR}$ spectra were measured in $\mathrm{CDCl}_{3}$ with tetramethylsilane as an internal standard at $300 \mathrm{MHz}$. IR spectra were recorded on a FTIR spectrophotometer. HPLC was carried out equipped with $\mathrm{C}_{18}$ and chiral columns. The solvents were of analytical grade.

\section{2. ${ }^{1} \mathrm{H}$ NMR spectral data}

(S)-1 in $\mathrm{CDCl}_{3}$

\section{Figure S1}

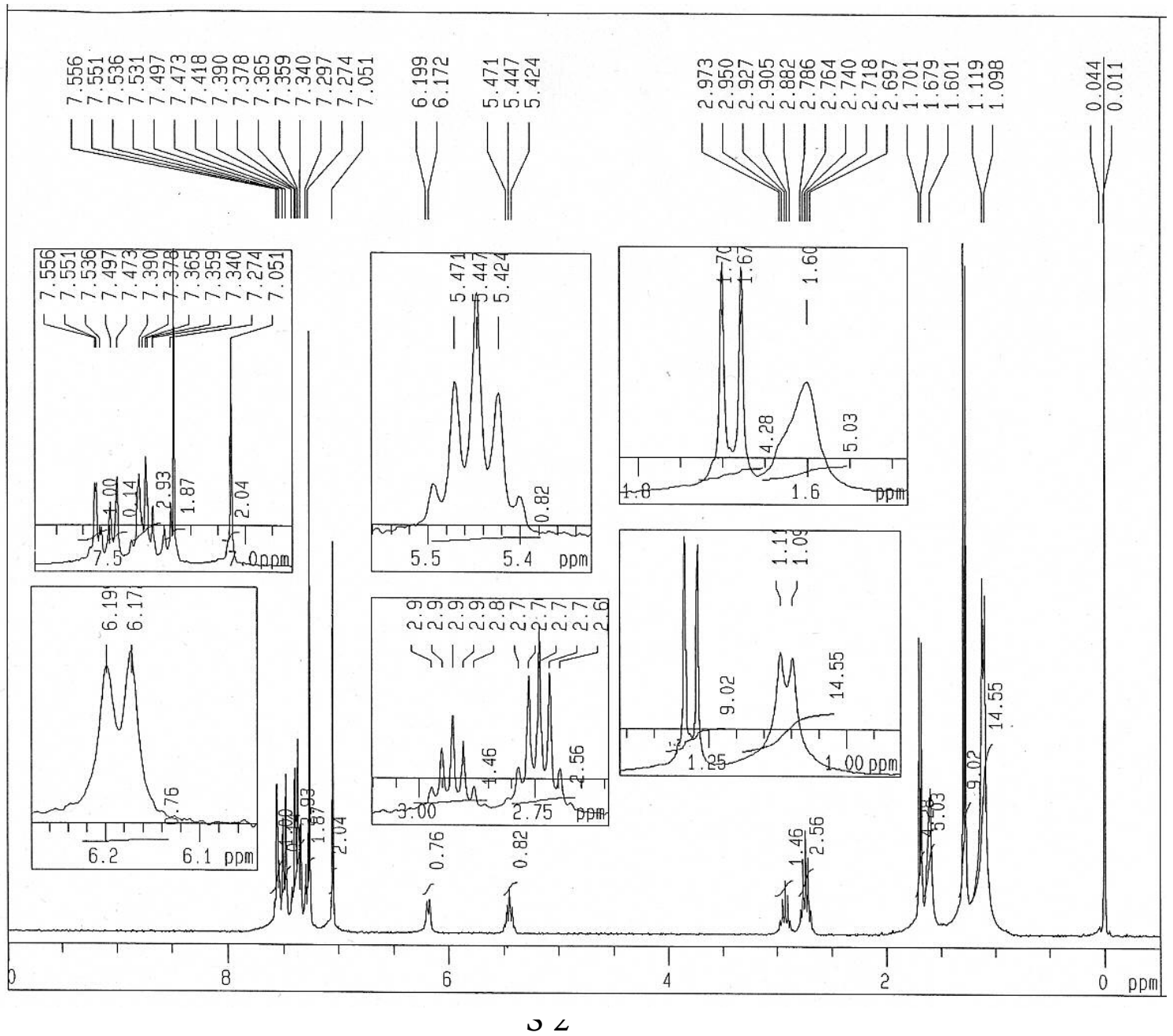


$(R, S)-2$ in $\mathrm{CDCl}_{3}$

\section{Figure S2}

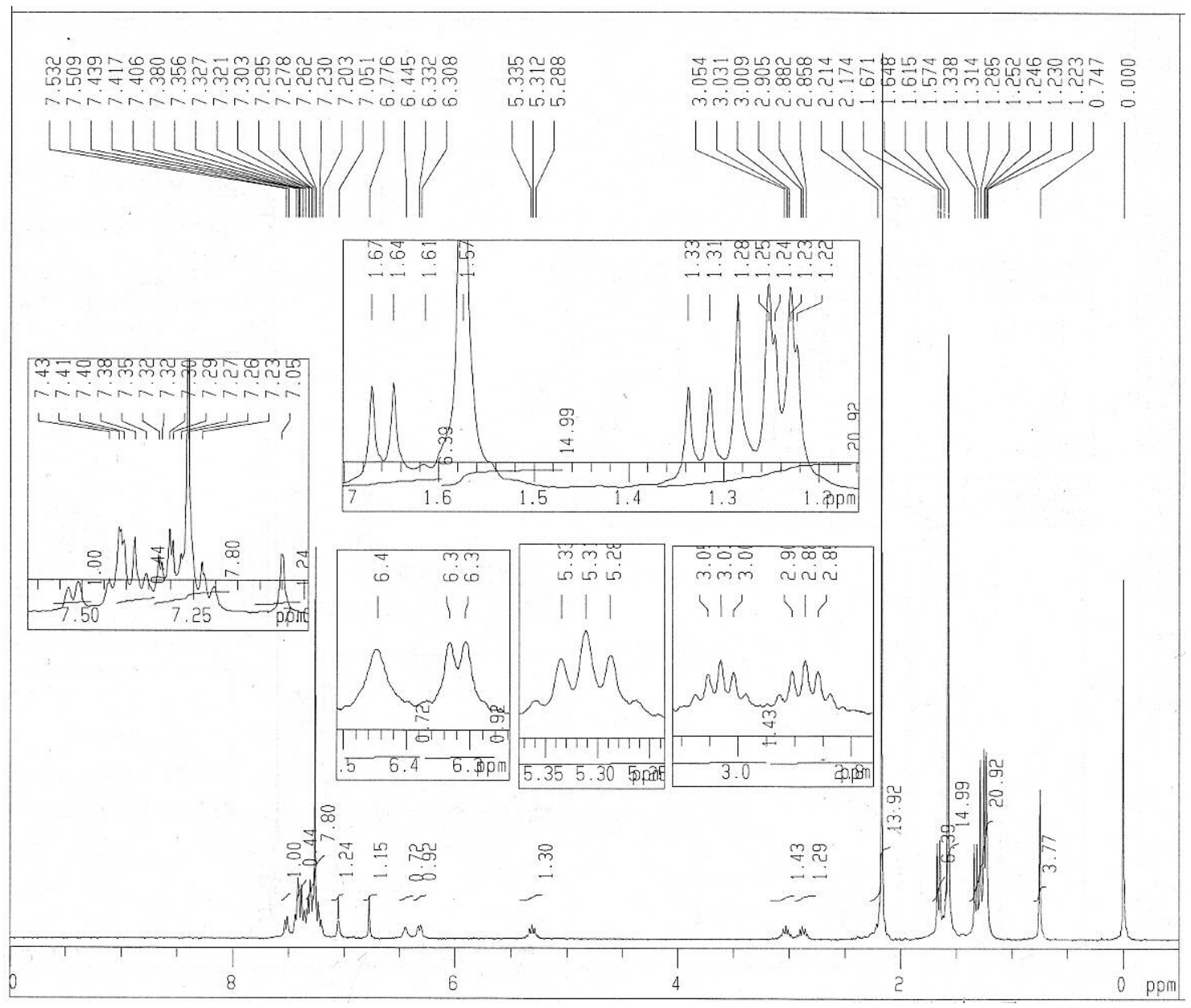


$(S, S)$-2 in $\mathrm{CDCl}_{3}$

\section{Figure S3}

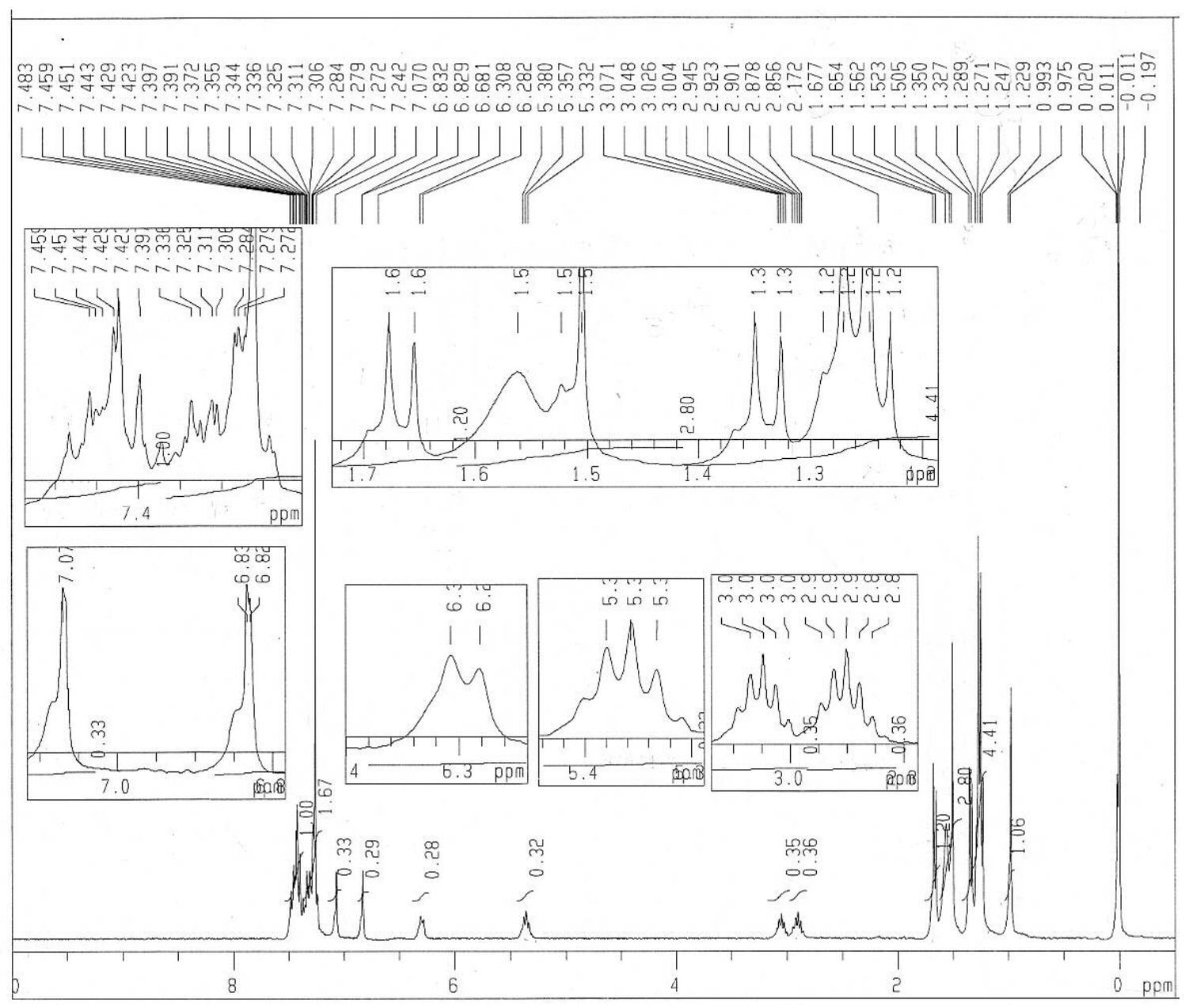

